Ann. Geophysicae 16, 882-888 (1998) @ CGS - Springer-Verlag 1998

\title{
Analysis of the effect of the coastal discontinuity on near-surface flow
}

\author{
S. C. Pryor ${ }^{1}$, R. J. Barthelmie ${ }^{1,2}$ \\ ${ }^{1}$ Climate and Meteorology Program, Department of Geography, Indiana University, Bloomington, IN 47405, USA \\ Fax: + 1812855 1661; e-mail: spryor@indiana.edu \\ ${ }^{2}$ Department of Wind Energy and Atmospheric Physics, Risø National Laboratory, Roskilde, Denmark
}

Received: 23 May 1997 / Revised; 28 November 1997 / Accepted: 5 December 1997

\begin{abstract}
Conditional sampling is used herein to examine the effect of fetch, stability, and surface roughness changes on wind speeds in the coastal zone. Using data from an offshore wind farm it is shown that at a distance of $1.2-1.7 \mathrm{~km}$ from the coast, up to a height of $20 \mathrm{~m}$ above the surface, differences in wind speed distributions from onshore and offshore masts are statistically significant for flow moving offshore under all stability conditions. In contrast, differences between the distribution of wind speeds at 38 and $48 \mathrm{~m}$ at masts located at the coast and in the coastal zone are not significant for flow moving offshore, indicating that flow at these heights is not fully adjusted to the change in surface roughness (land to sea). These findings are in accordance with calculations of the internal boundary layer (IBL) height which indicate that the IBL would frequently be below the two upper measurement heights at $1.2-1.6 \mathrm{~km}$ from the coast. The analyses presented here indicate that the wind speed distribution at a potential offshore wind farm site is not solely dependent on fetch (distance from the coast) but also depends on the stability climate.
\end{abstract}

Key words. Meteorology and atmospheric dynamics . Mesoscale meteorology · Ocean-atmosphere interaction - Marine meteorology

\section{Introduction and objectives}

Modification of flow in the coastal zone occurs as a result of stability and roughness changes, and has implications for applications such as offshore wind energy production and atmospheric dispersion and

Correspondence to: S. C. Pryor deposition in coastal regions. Because of the relative lack of in situ measurements in the coastal zone, measurements from nearby land sites are often extrapolated to produce estimates for offshore sites (Hsu, 1988); however, flow at different heights moving offshore is differentially influenced by roughness and stability changes introduced by the surface discontinuity (Barthelmie et al., 1996), and assumptions regarding conditions over sea (e.g., near-neutral stability) may be frequently violated.

Data used herein were collected at an offshore wind farm located at Vindeby, Denmark, on three masts shown in Fig. 1; one located at the coast (LM) and two located at minimum distances from the coast of 1270 and $1630 \mathrm{~m}$ (SMS and SMW, respectively). As shown in Fig. 1, the wind farm, which is located in a relatively enclosed sea north of the island of Lolland, comprises 11 turbines arranged in two parallel rows oriented northwest-southeast. As described in Barthelmie et al. (1997), the sea masts are placed in such a way that they take the position of an additional turbine located to the south (SMS) and west of the turbines (SMW) at a distance of $300 \mathrm{~m}$ from the closest turbine. Each meteorological mast is equipped with a minimum of four cup anemometers (at 7, 20, 38 and $48 \mathrm{~m}$ ), and two wind vanes. Additional instrumentation is comprehensive and includes thermistors, sonic anemometers, pressure, humidity and wave height sensors (Barthelmie et al., 1994). Data presented herein are half-hourly averages from January to December 1994.

The objectives of this paper are to use conditional sampling of observed data from the Vindeby project in order:

1. To elucidate relationships between differences in wind speeds measured on- and offshore and flow direction (onshore or offshore), fetch (distance from the coastal discontinuity), stability (classes defined using the Monin-Obukhov length), and surface roughness changes $\left(z_{0}\right.$ over land and $z_{0}$ over sea). Data from Vindeby indicate that on average wind speeds at the sea masts are $5 \%$ higher than those at the land mast. 

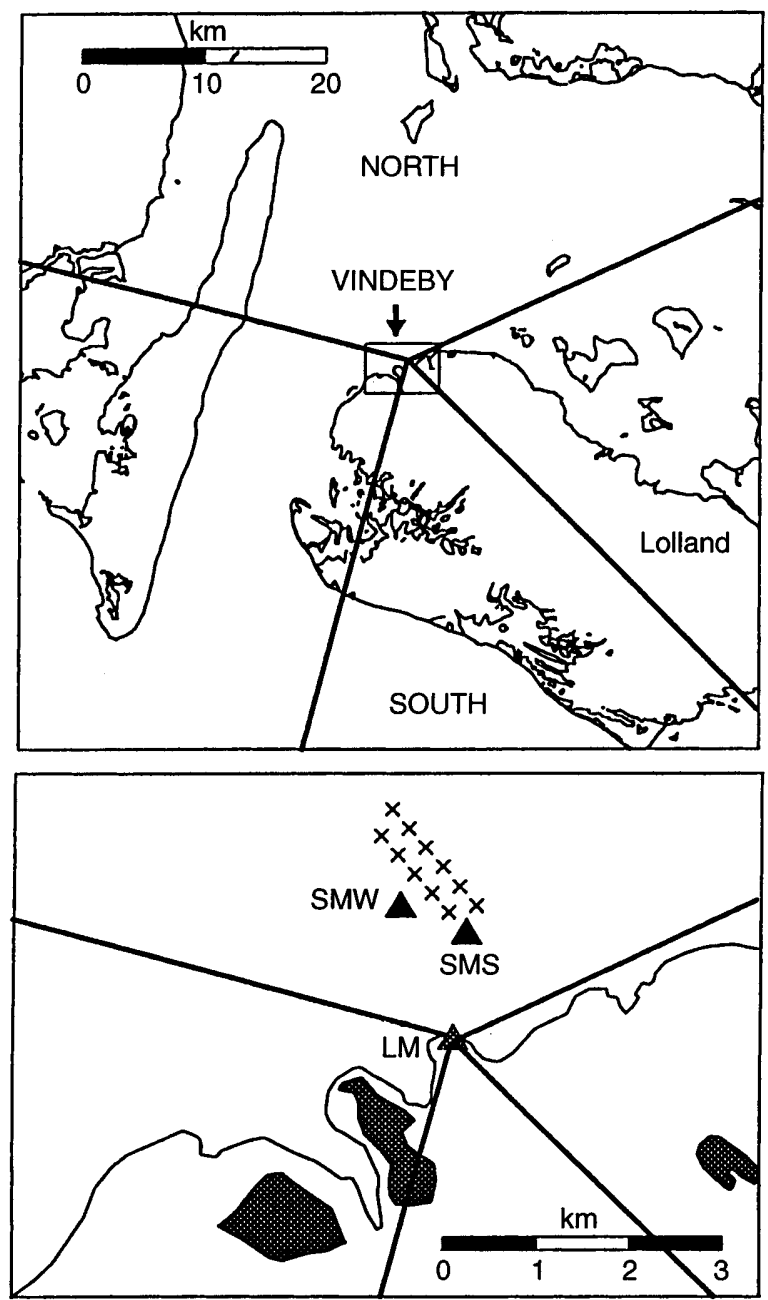

Fig. 1. Map of the Vindeby monitoring location. The crosses indicate the location of wind turbines. The measurement masts are indicated by the solid triangles and the identifiers: $\mathrm{LM}=$ land mast, $\mathrm{SMS}=$ sea mast south, SMW = sea mast west

Herein, we examine whether higher wind speeds over sea are consistent across the entire wind speed distributions (over land and sea), evident at all measurement heights (up to $48 \mathrm{~m}$ above the surface), and dependent on stability and fetch conditions.

2. To examine whether offshore flow at a distance of $1.2-1.7 \mathrm{~km}$ from the coast and a height of up to $48 \mathrm{~m}$ from the surface is fully adjusted subsequent to the coastal discontinuity. Specifically to examine whether the upper measurement heights are frequently within the internal boundary layer (IBL) generated by the surface discontinuity as flow moves offshore. This analysis has direct implications for siting of wind farms in the coastal zone to maximize power output.

\section{Data analyses}

\subsection{Meteorological data}

Herein, wind speed data are conditionally sampled by wind direction sector and stability. Two wind direction sectors are used: a north sector from $285^{\circ}$ to $65^{\circ}$ (flow directly over sea to all three masts) and a south sector from $135^{\circ}$ to $195^{\circ}$ [flow is over at least $10 \mathrm{~km}$ of land prior to observation at LM and then has a sea fetch of between 1 and $2 \mathrm{~km}$ before reaching the sea masts (SMS and SMW)]. These two wind direction sectors are shown in Fig. 1. Stability is characterized using the MoninObukhov length, $L$, determined using parameterizations given in Beljaars et al. (1989) and applied in Van Wijk et al. (1990).

Monin-Obukhov lengths at LM were calculated using wind speed at a height of $20 \mathrm{~m}$, temperature difference $\Delta T(16-8 \mathrm{~m})$ and absolute temperature at $8 \mathrm{~m}$. Monin-Obukhov lengths at the sea masts were calculated using wind speed at a height of $20 \mathrm{~m}, \Delta T(21-8 \mathrm{~m})$ and absolute temperature at $8 \mathrm{~m}$. Using the parameterization of Beljaars et al. (1989), the sign of the Monin-Obukhov length is determined by the temperature profile. The magnitude is determined by an iterative process where an initial value is estimated assuming that the wind speed profile is close to neutral and determining the friction velocity based on wind speed and roughness length [assigned for land (Barthelmie et al., 1994) and calculated for sea according to the Charnock equation (Charnock, 1955)]. The value of the Monin-Obukhov length is proportional to the cube of the friction velocity. Hence, in this case, the nominal height to which the Monin-Obukhov length is assigned is the height of the wind speed measurement. Stability classes used herein are defined on the basis of Van Wijk et al. (1990) where $|L|>1000 \mathrm{~m}$ indicates near-neutral conditions, $-1000<L<0 \mathrm{~m}$ indicates unstable conditions, and $1000>L>0 \mathrm{~m}$ indicates stable conditions.

\subsection{Conditional sampling of wind speed data}

Using conditional sampling, wind speed data at each measurement height $(7,20,38$, and $48 \mathrm{~m})$ were selected by directional sector (north or south as defined by wind direction at $20 \mathrm{~m}$ at $\mathrm{LM}$ ) and stability class for all cases when stability conditions at the two masts (LM and SMS or LM and SMW) were in the same class (i.e., stable, near-neutral, or unstable as defined by $L$ ). Wind speed data from all three masts and $L$ and wind direction from LM are concurrently available for 8309 time-periods. As shown in Table 1, the data selection criteria reduce the number of observations available for analysis particularly for the unstable case with flow from the south sector.

Figure 2 shows wind speed distributions from SMS and LM by stability class and wind direction sector at $7 \mathrm{~m}$. In accordance with a priori knowledge, with flow from the north sector wind speed distributions at all masts and all heights show similar behavior regardless of stability class. However, an exception is at $7 \mathrm{~m}$ in the near-neutral class when wind speeds are slightly higher at the sea masts (Fig. 2). The difference between wind speeds at the offshore mast and LM (lower wind speeds at LM) for near-neutral conditions with a north fetch are most pronounced at higher wind speeds and may reflect: 
Table 1. Statistical summary of analysis of the wind speed distributions by stability class $(\mathrm{S}=$ stable, $\mathrm{N}=$ near-neutral, $\mathrm{US}=$ unstable) and wind direction [NORTH $=$ flow over sea to all masts (wind direction: $285^{\circ}-65^{\circ}$ ), SOUTH $=$ flow over land to LM and then over sea to SMS and SMW (wind direction: $135^{\circ}$ $\left.195^{\circ}\right)$ ]. The first row for each stability class shows the total number of observations in that stability class by directional sector (e.g., there are 151 observations with near-neutral stability at both SMS and LM with flow from the south sector). The second row indicates the results of Kolmogorov-Smirnov test for the equality of distributions test applied to the wind speed data from the land mast (LM) and the respective sea mast (SMS or SMW) (e.g., the wind speed observations with near-neutral stability and flow from the south sector exhibit different distributions at the LM and SMS at the $99.9 \%$ confidence level). $H(\mathrm{~m})$ indicates the height of the measurements above the surface. The numbers in parentheses after the total counts indicate the number of observations in each stability - direction category from the nighttime hours / (defined as 7:01 p.m. - 7:00 a.m.)/ the number of observations in each category from the daytime hours (defined as 7:01 a.m - 7:00 p.m.)

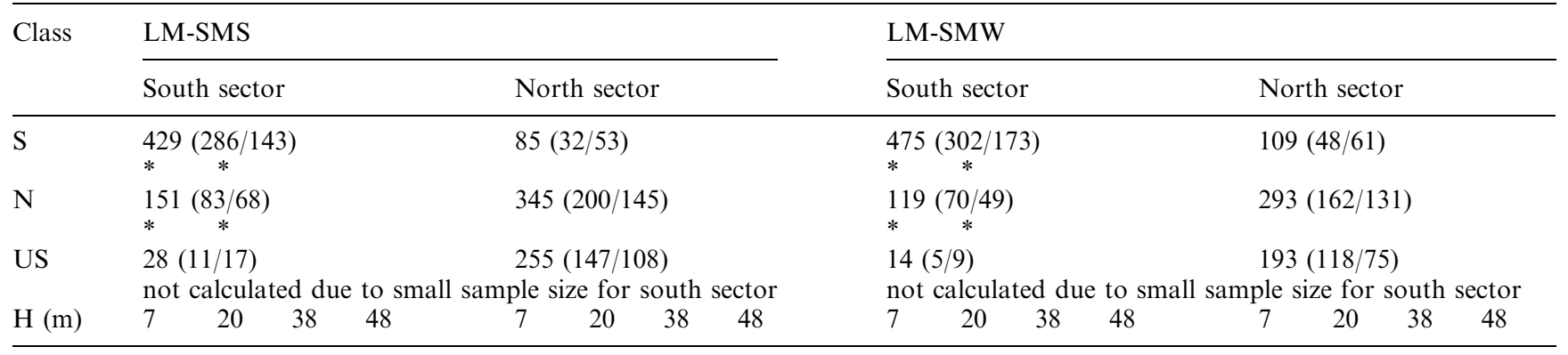

(* = significant at the $99.9 \%$ confidence level)
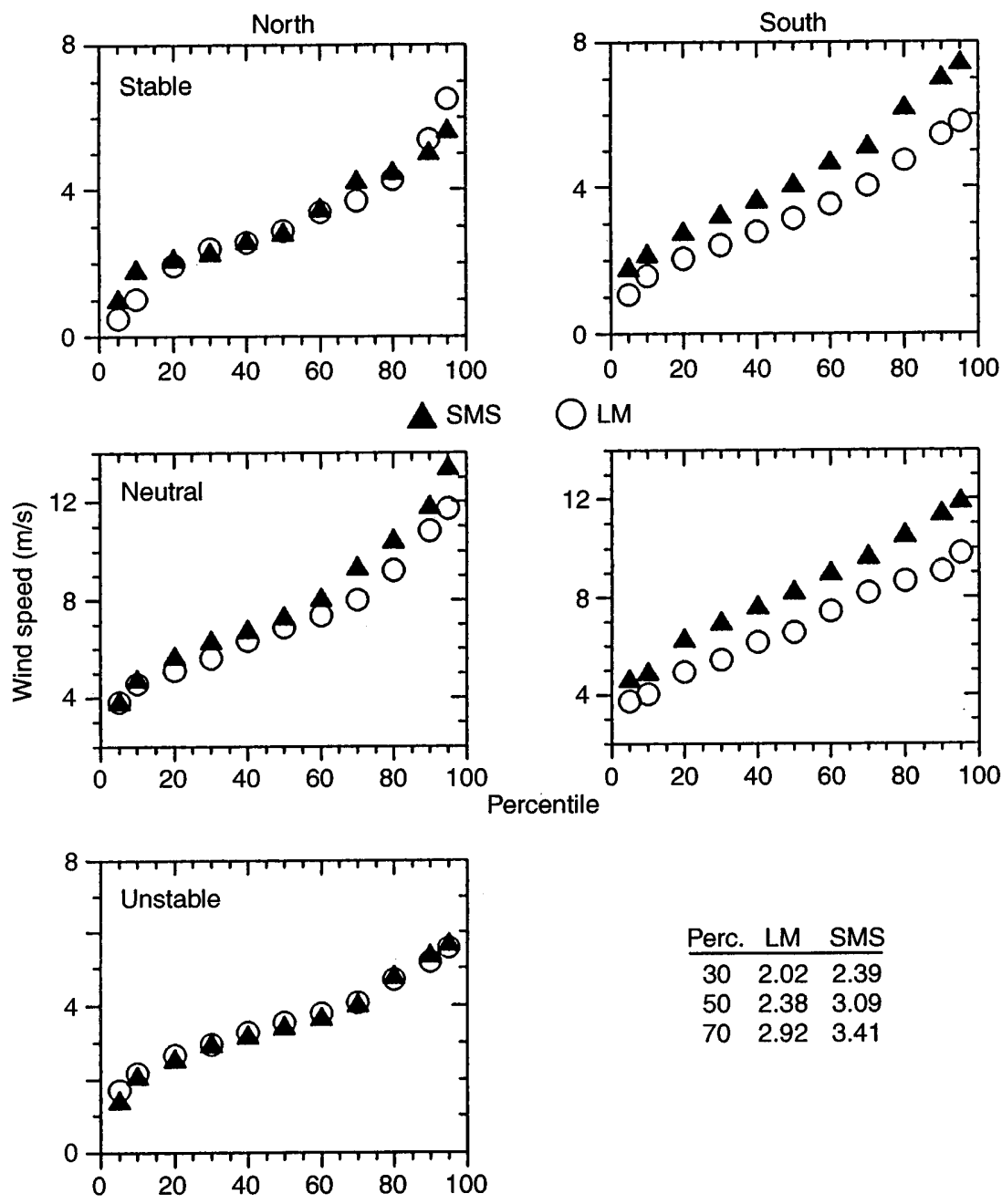

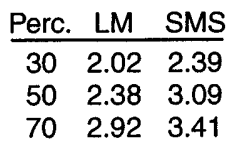

Fig. 2. Wind speed distributions $(\mathrm{m} / \mathrm{s})$ at $7 \mathrm{~m}$ height from LM and SMS by directional sector (wind direction) and stability class. Because of the low number of observations in the unstable class the entire distribution may not be characterized, and so the data for the $30^{\text {th }}, 50^{\text {th }}$, and $70^{\text {th }}$ percentiles are shown in the box (note: Perc. $=$ percentile) 
1. propagation of the effect of the surface discontinuity upwind of the island,

2. the effect of displacement of the mast from the coastal discontinuity (LM is $16 \mathrm{~m}$ from the coast),

3 . the effect of enhanced surface roughness at the coast due to the growth of reeds in summer (which would lead to higher momentum flux to the surface).

The distribution of wind speeds from the sea masts may incorporate the influence of wake and obstacle effects when the masts are in the lee of the wind turbines. Wake effects are defined here as deceleration in wind speed and increase in turbulence in the flow downwind of an operating wind turbine. To investigate the potential role of wake effects in inducing difference in the wind speed distributions measured at the sea and land masts for flow from the north sector, $5^{\circ}$ directional sectors associated with a primary wake effect (i.e., a turbine directly upstream of the mast at a distance of 300-500 m from the mast) were omitted from the data set and the wind speed distribution was recalculated for each measurement height at SMS and SMW. An example of the results of this reanalysis compared to the wind distribution characterized with the full data set is shown in Table 2 for SMS at the $7 \mathrm{~m}$ measurement height. The data contained in this table indicate that wake effects are associated with a decrease in wind speeds in near-neutral conditions of up to $5 \%$ relative to the sector 30 th, 50 th, and 70th percentile wind speed values, and at higher wind speeds under unstable and stable conditions. Similar results were found for the other measurement heights and for data from SMW. However, wake effects
Table 2. Investigation of wake effects. Variations in wind speed at SMS at $7 \mathrm{~m}$ measurement height for the north sector $\left(285^{\circ}-65^{\circ}\right)$ using all observations and excluding wind directions subject to wake effects based on the wind farm orientation (excluded sectors: $20^{\circ}$ $25^{\circ}$, and $315^{\circ}-325^{\circ}$ ). Note: The data contained in this table differ from those in Table 1 because here the wind direction is defined based on observations at SMS

\begin{tabular}{|c|c|c|c|c|c|c|}
\hline & \multicolumn{2}{|c|}{ Unstable } & \multicolumn{2}{|c|}{ Near-neutral } & \multicolumn{2}{|l|}{ Stable } \\
\hline \# of obs & 143 & 111 & 333 & 293 & 77 & 72 \\
\hline 30 th percentile & 2.99 & 3.04 & 6.94 & 7.18 & 2.63 & 2.64 \\
\hline 50 th percentile & 3.46 & 3.50 & 9.11 & 9.32 & 4.22 & 4.28 \\
\hline 70 th percentile & 4.08 & 4.24 & 10.73 & 11.25 & 5.02 & 5.07 \\
\hline
\end{tabular}
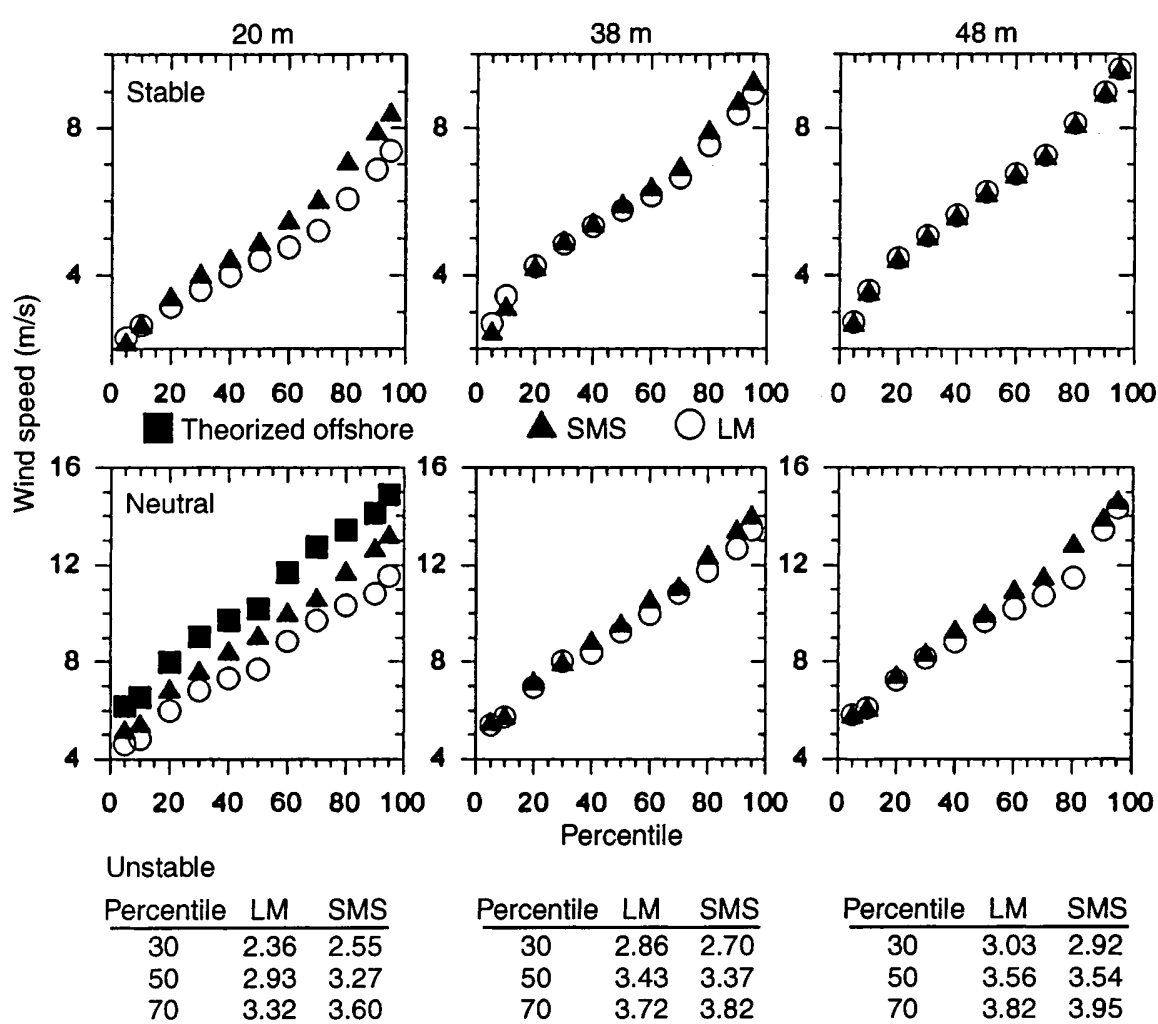

Fig. 3. Wind speed distributions $(\mathrm{m} / \mathrm{s})$ at 20, 38, and $48 \mathrm{~m}$ height from LM and SMS by $\mathrm{s}$ tability class for flow from the south sector. Also shown is a wind speed distribution at $20 \mathrm{~m}$ for near-neutral conditions derived theoretically, using the methodology described in the text. Because of the low number of observations in the unstable class the entire distribution may not be characterized and so the data for the $30^{\text {th }}, 50^{\text {th }}$, and $70^{\text {th }}$ percentiles are shown in the box (note: Perc. $=$ percentile) 
are not thought to substantially bias the comparisons of north sector wind speeds at the sea masts and LM because of the relatively low number of observations in sectors associated with direct turbine wakes.

Figure 3 shows wind speed distributions from LM and SMS at 20,38, and $48 \mathrm{~m}$ for flow from the south sector only. For offshore flow under near-neutral and stable conditions, higher winds are observed at SMS at $7 \mathrm{~m}$ (Fig. 2) and $20 \mathrm{~m}$ over the entire wind speed distribution. This is consistent with observations that sea surface roughness is between two and three orders of magnitude lower than that of a typical land surface. Frictional dissipation of momentum at the sea surface is significantly lower, hence in the absence of horizontal stability gradients near-surface flow accelerates in response to the change in roughness when flow moves offshore. The absolute magnitude of the differences in wind speed distributions are smaller in stable conditions because wind speeds are lower and thermal stratification inhibits momentum transfer from aloft and thus reduces the vertical propagation of the effects of reduced frictional dissipation of momentum over sea. Detailed interpretation of unstable cases with flow from the south sector is not possible due to the low number of observations; though the data also show evidence of higher wind speeds at SMS than LM under these conditions. At 38 and $48 \mathrm{~m}$ the upper quartile of the wind speed distributions under near-neutral and stable conditions show some evidence of higher wind speeds over sea. However, the differences are small, suggesting that at this distance from the coast wind speeds at these heights are not fully adjusted to the change in surface roughness.

\subsection{Quantitative analyses of the wind speed distributions}

In order to examine the differences in wind speed distributions at the on- and offshore masts by stability class and wind direction which are described qualitatively in the preceding text, three statistical techniques are employed: a Wilcoxon matched-pairs signed ranks test, the Kolmogorov-Smirnov equality of distributions test, and quantile-quantile plots. The Wilcoxon matched-pairs signed ranks test (Kennedy and Neville, 1986) is used to test the equality of matched pairs of observations (in this case the wind speed of observations from the LM and SMS and SMW conditionally sampled by sector and stability) using the following methodology. The difference score for each matched pair (coincident wind speed observations) is calculated for the data set and then ranked (from largest difference to smallest difference) regardless of sign. The rank scores for all positive values are summed and compared to the summed rank scores for the negative differences. If the two series (wind speed data sets) are drawn from the same population then each matched pair has the same probability of being positive or negative, if not the value of the actual rank score differences can be used to determine the confidence with which one can assert that the data sets are different. The Kolmogorov-Smirnov equality of distributions test (Kennedy and Neville,
1986) is used here to examine whether the form of the wind speed distributions at each measurement height sampled by stability class and fetch is statistically different at the land and sea masts. The KolmogorovSmirnov equality of distributions test is used to evaluate whether two distributions drawn from continuous (not categorical) data series differ and at what significance level. The two cumulative frequency distributions are compared by assuming that one conforms to an idealized distribution and then evaluating whether the other distribution shows similar (identical) form. Empirical quantile-quantile plots (Karl, 1978) are used herein to examine the differences in wind speed distributions from the two sea masts. In quantile-quantile plots, the data value for a given quantile are plotted against the data value for the same quantile from another data set. If the distributions are identical then the plotted data will form a straight line of slope equal to 1 and intercepting zero. These plots permit comparison of wind speeds across the entire distributions and their use does not require any assumptions about the form of the underlying data distribution.

In accordance with qualitative assessment of Figs. 2 and 3, a Wilcoxon matched-pairs signed ranks test applied to compare the magnitude of observations from the LM and SMS and SMW conditionally sampled by wind direction and stability, indicates that wind speeds are significantly and consistently higher at the sea masts when the flow is from the south sector, but are not consistently higher with flow from the north sector except at $7 \mathrm{~m}$ height. The Kolmogorov-Smirnov equality of distributions test (Kennedy and Neville, 1986) was then used to examine whether the form of the wind speed distributions at each measurement height sampled by stability class and fetch are statistically different at the land and sea masts. The results are shown in Table 1 and indicate that at 7 and $20 \mathrm{~m}$ height the form of the distributions from the LM are statistically different from those at SMS and SMW, but not at 38 and $48 \mathrm{~m}$. Note, in the unstable case, due to the small number of observations, only the equality of median values was tested and was found to indicate significant differences at the two lower measurement heights $(7$ and $20 \mathrm{~m})$. The change in the form of the distributions (as indicated by the Kolmogorov-Smirnov test) indicates a nonlinear response to the surface forcing which is amplified at high wind speeds.

For applications such as offshore wind energy it is important to assess at what distance from the coast will flow moving offshore be fully adjusted to the reduced surface friction and hence attain maximum wind speeds subsequent to passing over the coastal discontinuity. To examine whether flow has attained equilibrium subsequent to the surface discontinuity at the offshore masts at the Vindeby wind farm, theoretical wind speeds over sea at $20 \mathrm{~m}$ height were derived using the following methodology. Theoretical wind speeds are derived for a land surface through iterative solution of the geostrophic drag law (Garratt, 1992) and the logarithmic wind speed profile with a roughness length of $0.05 \mathrm{~m}$ [appropriate for Vindeby (Barthelmie et al., 1997)]. Over sea, the same 
procedure is used except that roughness is calculated using the Charnock equation (Charnock, 1955). Thus, the theoretically derived offshore wind speeds shown in Fig. 3 were calculated from the wind speed over land using the assumptions that the geostrophic wind speed has the same value in both cases, of near-neutral stability, and that flow is at equilibrium with the respective surfaces (land or sea) (Barthelmie, 1998). These values can therefore be considered theoretical maximal increases in wind speed moving offshore due to surface roughness change alone. According to this logic, comparison of the observed wind speed at SMS and theorized wind speeds indicate that even at $1270 \mathrm{~m}$ from the coastal discontinuity the flow is not fully adjusted to the surface roughness change at $20 \mathrm{~m}$ height (Fig. 3).

For a number of applications it is also important to consider vertical propagation within the atmosphere of changes caused by a discontinuity in surface characteristics. Internal boundary layers are a theoretical tool used to describe the depth of the adjusted flow layer subsequent to passing over a discontinuity (Bergstrom et al., 1988). The height of the internal boundary layer (IBL) is assumed to increase as a function of roughness and stability conditions downwind of the discontinuity and to indicate the height at which the flow is at equilibrium with the 'new' surface conditions. From Fig. 3 and Table 1 it appears that wind speed distributions with flow from the south sector at $48 \mathrm{~m}$ and to a lesser extent at $38 \mathrm{~m}$ are unaffected by the lower surface roughness over sea, which implies that at these distances from the coast the flow at these heights is not fully adjusted to the 'new' surface, and hence that the IBL height is frequently lower than $48 \mathrm{~m}$. This hypothesis was tested by calculating the IBL height for each data record according to the Monin-Obukhov length over sea [based on Bergstrom et al. (1988)], where $h$ $=0.2 x^{(0.78-0.33 z / L)}, x=$ fetch, $z=$ height at which $L$ is defined $(20 \mathrm{~m})$. The results of these calculations indicate a median IBL height of 48 and $57 \mathrm{~m}$ for SMS and SMW, respectively, indicating that on average the 48-m level would be above or near to the IBL height and hence only weakly affected by the reduction in surface roughness over sea. Further support for this hypothesis is obtained from analysis presented in Fig. 4, which shows empirical quantile-quantile plots for SMS and SMW at 38 and $48 \mathrm{~m}$ under near-neutral conditions for flow from the south sector. These plots indicate that across the entire distribution of wind speeds, wind speed values associated with specific quantiles are slightly lower at SMS than at SMW.
This is in accordance with the observation that SMW is located further from the coast and that the IBL height should be higher at this location.

\section{Discussion and conclusions}

Conditional sampling of data collected at Vindeby in Denmark was used to examine the relationships between wind speed distributions at multiple heights at on- and offshore locations. Wind speed distributions from offshore masts located over $1 \mathrm{~km}$ from the coast indicate that whilst near-surface flow is at least partially adjusted to the change in surface roughness (land-sea) over this distance from the coast, on average, the flow is not at equilibrium with the sea surface. Flow at 38 and $48 \mathrm{~m}$ above the surface exhibits little evidence of acceleration due to decreased roughness as the flow moves offshore regardless of stability conditions. This is in accordance with calculations of the IBL height (based on MoninObukhov length) which show that the IBL is frequently below the height of observation.

As shown in Table 1 there is a difference between the daytime and nighttime frequency of flow from different wind direction sectors and stability classes. It has been

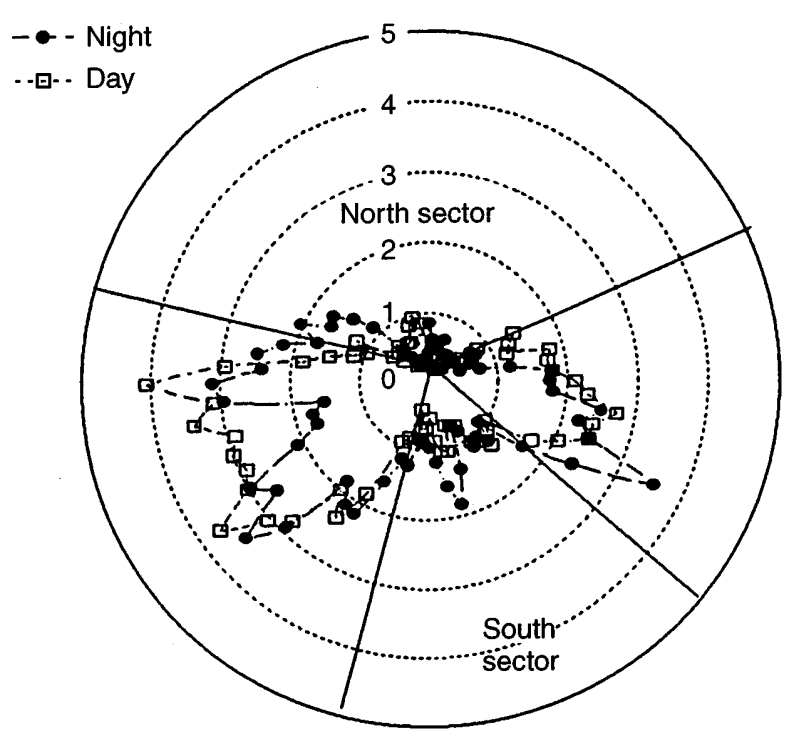

Fig. 5. The relative frequency (expressed in percent) of flow from $5^{\circ}$ sectors at LM for the night hours (defined as 7:01 p.m.-7:00 a.m.) and the daytime hours (defined as 7:01 a.m.-7:00 p.m.)

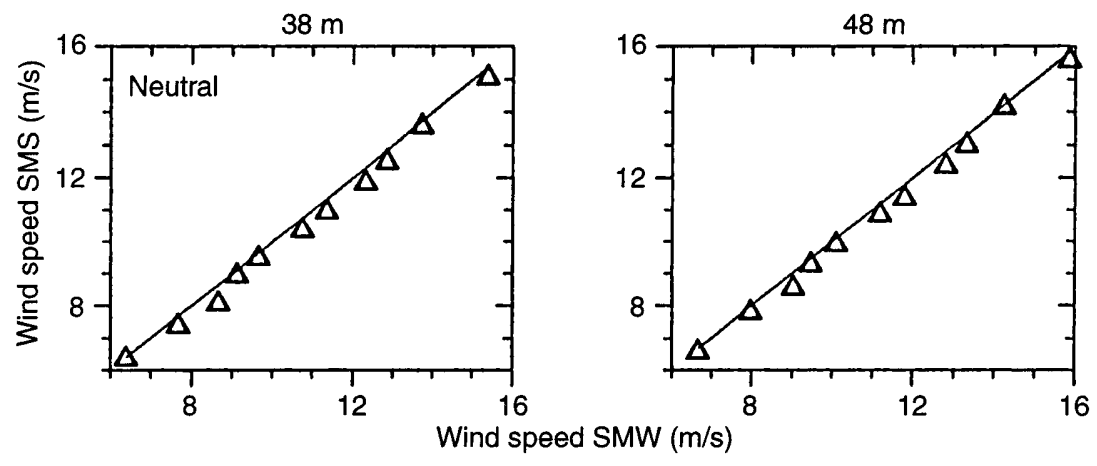

Fig. 4. Empirical quantile-quantile plots from wind speeds $(\mathrm{m} / \mathrm{s})$ at SMS and SMW at 38 and $48 \mathrm{~m}$ under near-neutral conditions with flow from the south sector 
suggested that this is a function of a thermally generated mesoscale circulation (specifically a seabreeze-landbreeze circulation). However, wind-roses generated for flow in $5^{\circ}$ sectors for the daytime (defined as 7:01 a.m. $-7: 00$ p.m.) and nighttime (defined as 7:01 p.m. $-7: 00$ a.m.) hours do not appear to indicate a dominant seabreeze-landbreeze circulation generated by the island of Lolland. With regard to the north and south sectors used herein, as shown in Fig. 5, the wind-roses indicate relatively similar wind directions in the day- and nighttime hours. The implication is that the diurnal differences evident in Table 1 and related analyses are due to diurnal variability of stability and that the diurnal bias is due to the criteria that onshore and offshore stability are in the same class (stable, nearneutral, or unstable as defined by the Monin-Obukhov length). Hence, although thermally generated effects are clearly impacting the analyses presented here, it appears to be due primarily to stability effects and not a thermally driven mesoscale circulation.

The analyses presented here indicate that the wind speed distribution in the coastal zone is not solely dependent on fetch (distance from the coast) but also depends on the stability climate. Future work will focus on quantifying the roles of roughness and stability changes on momentum transfer in the coastal zone and the spatial and temporal scales of flow adjustment.

Acknowledgements. We are grateful to our colleagues at Risø National Laboratory who collected the data presented herein, and to Dr. Branko Grisogono for his helpful comments and suggestions. This paper was conceived whilst the first author was on leave at Risø National Laboratory on a Presidents Award from Indiana University, and was substantially improved by the comments of two anonymous reviewers.

Topical Editor G.-P. Duvel thanks H. Bergstrom and another referee for their help in evaluating this paper.

\section{References}

Barthelmie, R. J., The effects of atmospheric stability on coastal wind climates, Meteorol. Appl., in press, 1998.

Barthelmie, R. J., M. S. Courtney, J. Højstrup, and P. Sanderhoff, The Vindeby Project: a description, Ris $\varnothing-R-741(E N)$, Risø National Laboratory, Denmark, 1994.

Barthelmie, R. J., B. Grisogono, and S.C. Pryor, Observations and simulations of diurnal cycles of near-surface wind speeds over land and sea. J. Geophys. Res., 101, 21 327-21 337, 1996.

Barthelmie, R. J., M. S. Courtney, J. Højstrup, and S. E. Larsen, Meteorological aspects of off-shore wind energy-observations from the Vindeby wind farm. J. Wind Eng. Ind. Aerodyn., 62, 191-211, 1997.

Beljaars, A. C. M., A. A. M. Holtslag, and R. M. van Westrhenen, Description of a software library for the calculation of surface fluxes. Tech. Rep. TR-112, KNMI, De Bilt, Netherlands, 1989.

Bergstrom, H., P. -E. Johansson, and A. -S. Smedman, A study of wind speed modification and internal boundary-layer heights in a coastal region. Boundary-Layer Meteorol., 42, 313-335, 1988.

Charnock, H., Wind stress on a water surface. Q. J. R. Meteorol. Soc., 81, 639, 1955.

Garratt, J. R., The atmospheric boundary layer, Cambridge atmospheric and space science series, Cambridge University Press, Cambridge, 1992.

Hsu, S. A., Coastal meteorology, Academic Press, San Diego, 1988.

Karl, T. R., Day-of-the-week variations of photochemical pollutants in the St. Louis area, Atmos. Environ. 12, 1657-1667, 1978.

Kennedy, J. B., and A. M. Neville, Basic statistical methods for engineers and scientists, Harper and Row, New York, 1986.

Van Wijk, A. J. M., A. C. M. Beljaars, A. A. M. Holtslag, and W. C. Turkenburg, Evaluation of stability corrections in wind speed profiles over the North Sea. J. Wind Eng. Ind. Aerodyn., 33, 551-566, 1990. 